\title{
Tramadol suppository poisoning in children of Bangladesh
}

\author{
MAKSUDUR RAHMAN ${ }^{1}$, MAK AZAD CHOWDHURY ${ }^{2}$, MD MAHBUBUL HOQUE ${ }^{3}$, MD. MONIR \\ HOSSAIN $^{3}$, GOLAM MORSHED SUMAN ${ }^{4}$
}

\begin{abstract}
Background: Tramadol is an analgesic agent utilized in the treatment of different types of pain. Recently it was found that a few cases of tramadol poisoning were observed in hospitalized children. In all cases, it happened due to accidental administration of tramadol suppository.
\end{abstract}

Objective: The aim of this study was to determine the clinical manifestations of tramadol suppository poisoning in children and to create public awareness about the prevention of this suppository poisoning.

Materials \& Methods: This was an observational, retrospective, single-center caseseries study of hospitalized children in Dhaka Shishu Hospital during the periods of July 2016 to March 2017. Eleven patients with history of accidental intake of tramadol suppositories were enrolled in this study. Data regarding risk factors and clinical features were recorded and analyzed.

Results: In this study, 7/11(64\%) cases were male and 4/11(36\%) female. Mean age was 7.8 month and mean duration of hospital stay was 46.4 hours. Parecetamol in $2 / 11$ (18\%) cases and glycerin suppository in 9/11(82\%) cases were main drugs that were supposed to be introduced instead of tramadol. Keeping drugs in same containers (11/11), similarities of suppository's size, shape and color (11/11) were found as causes of mistakes in this study. Main clinical features were drowsiness in $4 / 11(36 \%)$ cases, tachycardia in 3/11(27\%) cases and one case died.

Conclusions: More cautiousness of parents, dissimilarity among different suppository in color size, shape and using of different containers of drugs may be the preventive way of this poisoning.

Key words-Tramadol poisoning, Tramadol suppository

\section{Introduction}

In last few years, tramadol, which is an analogue of codeine, has become popularity as an analgesic agent. ${ }^{1}$ This drug is utilized in the treatment of different types of pain. ${ }^{2}$ It's work on pain relief is by acting both as a central opiate agonist and central nervous system (CNS) reuptake inhibitor of norepinephrine and serotonin ${ }^{1,3,4}$ Tramadol is

1. Associate Professor, Department of neonatology, $\mathrm{BICH}$, Dhaka Shishu (Children) Hospital, Dhaka.

2. Professor \& Head, Department of neonatology, $\mathrm{BICH}$, Dhaka Shishu (Children) Hospital, Dhaka.

3. Professor, Department of neonatology, $\mathrm{BICH}$, Dhaka Shishu (Children) Hospital, Dhaka.

4. Consultant, Care Medical College Hospital, Dhaka.

Correspondence: Dr.Maksudur Rahman, Associate professor, Department of neonatology, BICH, Dhaka Shishu (Children) Hospital, Dhaka. E-mail:maksuddr@gmail.com

Received: 12/12/2018

Accepted: 19/11/2019 administered orally, rectally, sustained release, and in solution for IV/IM administration. ${ }^{5}$ In paediatric age group, there is limited uses of tramadol. It is using at a dose of doses of $1-3 \mathrm{mg} / \mathrm{kg} /$ day every $4-6 \mathrm{~h}$ in children older than four years. But its safety in children younger than 12 years of age has not been confirmed. ${ }^{6-10}$

There is few literature on pediatric tramadol intoxication that occurred during its uses in therapeutic purpose. ${ }^{11-12}$ Literature on nontherapeutic exposures is also less in pediatrics age group. ${ }^{5}$ Recently a few cases of tramadol poisoning were observed in hospitalized children in Bangladesh. In all cases, it happened due to accidental administration of tramadol suppository per rectal instead of other drugs like paracetamol or glycerin suppository. Parents of all level of socioeconomic 
condition and educational qualification were found to do this mistake.

The clinical features of tramadol intoxication include CNS (central nervous system) and respiratory depression including apnea and serotonin syndrome. The serotonin syndrome causes altered mental status (agitation, anxiety, disorientation, restlessness, and excitement), neuromuscular abnormalities (tremor, clonus, hyperreflexia, muscle rigidity, bilateral babinski sign, akathisia), and autonomic hyperactivity (hypertension, tachycardia, tachypnea, hyperthermia, vomiting, diarrhea, arrhythmias, shivering). Both mydriasis and miosis can occurs in tramadol poisoning. ${ }^{1,5,13}$ The aim of this study was to determine the clinical manifestations \& causes of tramadol suppository poisoning in children and to create public awareness about the prevention of this poisoning.

\section{Materials \& Methods}

This was an observational, retrospective, singlecenter case-series study of hospitalized children, in Dhaka Shishu Hospital during the periods of July 2016 to March 2017. Eleven children with history of accidental intake of tramadol suppositories were enrolled in this study. Data regarding age of patients, time to reach hospital, parent's education and economic condition, size, shape, color and dose of suppository, clinical features, consciousness, cardiorespiratory status (e.g.tachycardia, bradycardia, respiratory depression, apnea, seizure) and tonicity at admission and during hospital stay were taken. Pupil's size was also examined. Investigation like ABG (arterial blood gases analysis) was done along with other relevant laboratory investigations. Use of ventilator and naloxone were taken. Toxicological diagnosis was not done. Hospital stay and mortality were recorded. Then all the data were analyzed by frequency distributions with the help of SPSS version- 17.

\section{Results}

In this study, 7/11(64\%) cases were male and 4/ $11(36 \%)$ female. Mean age was 7.8 month (range 27 days-18 month). Mean duration of hospital stay was 46.4 hours (range $11 \mathrm{~h}-168 \mathrm{~h}$ ). Mean time to reach the hospital was 5.2 hours (range $3 \mathrm{~h}-12 \mathrm{~h}$ ). Parecetamol in $2(18 \%)$ cases and glycerin suppository in $9(82 \%)$ cases were main drugs that were supposed to be introduced instead of tramadol.
Main clinical features were drowsiness in $4(36 \%)$ cases, tachycardia in $3(27 \%)$ cases, semi consciousness in $2(18 \%)$ cases, unconsciousness in $2(18 \%)$ cases, seizure in $2(18 \%)$ cases, apnea in $2(18 \%)$ cases, shallow respiration in $2(18 \%)$ cases, hypotension in $1(9 \%)$ ) case, and hyper tonicity in $2(18 \%)$ cases. Ventilator was required in $2(18 \%)$ cases having septicemia. Respiratory acidosis was present in two cases and metabolic acidosis was present in one case. One patient got naloxone as antidote and one patient died. Each mother had individual occupation including lawyer in $1(9 \%)$ case, businessmanin $3(27 \%)$ cases, day laborer $3(27 \%)$ cases, service holder in $3(27 \%)$ cases, and even doctor in $1(9 \%)$ case. Mother's anxiety (6/11), keeping drugs in same containers (11/11), similarities of suppository's size, shape and color (11/11) were the main causes of mistakes in this study.

Table I

Clinical manifestations of tramadol poisoning (total case $n=11$ )

\begin{tabular}{lc}
\hline Clinical manifestations & $\begin{array}{c}\text { No of case } \\
\text { (percentage) }\end{array}$ \\
\hline Drowsiness & $4(36 \%)$ \\
Semiconscious & $2(18 \%)$ \\
Unconscious & $2(18 \%)$ \\
Seizure & $2(18 \%)$ \\
Hypertonicity & $2(18 \%)$ \\
Shallow respiration & $2(18 \%)$ \\
Apnea & $2(18 \%)$ \\
Tachycardia & $3(27 \%)$ \\
Hypotension & $1(9 \%)$ \\
Miosis & $2(18 \%)$ \\
\hline
\end{tabular}

Table-II

Occupations of Caregiver (total case $n=11$ )

\begin{tabular}{lc}
\hline $\begin{array}{l}\text { Occupation of Care } \\
\text { Givers }\end{array}$ & $\begin{array}{c}\text { No of case } \\
\text { (percentage) }\end{array}$ \\
\hline Lawyer & $1(9 \%)$ \\
Service Holder & $3(22 \%)$ \\
House wife & $3(27 \%)$ \\
Day laborer & $3(17 \%)$ \\
Physician & $1(9 \%)$ \\
\hline
\end{tabular}


Table- III

Cause of Mistake (total case $n=11$ )

\begin{tabular}{lc}
\hline Causes of mistake & $\begin{array}{c}\text { No of case } \\
\text { (percentage) }\end{array}$ \\
\hline Mothers/care givers anxiety & $6(54 \%)$ \\
Keeping drugs in same container & $11(100 \%)$ \\
Similarities of suppositories in size, & $11(100 \%)$ \\
shape and color & \\
\hline
\end{tabular}

\section{Discussion}

In this study total eleven cases of accidental tramadol suppository poisoning were found and Parecetamol in two cases and glycerin suppository in nine cases were main drugs that were supposed to be ingested instead of tramadol. Published data was present regarding oral, parenteral administration of tramadol intoxication but study only on per rectal accidental tramadol suppository poisoning was very rare. In one study administration of a $100 \mathrm{mg}$ suppository to a 6 -month-old child was seen. ${ }^{5}$

In this study seven (64\%) cases were male and $4(36 \%)$ female. Mean age was 7.8 months (range 27 days $-18 \mathrm{~m}$ ). In the study of Hossein et at. ${ }^{5}$ mean age of the patients was $3.7 \pm 2.9$ years (range; 9 months to 10 years) which was more than our study. In our study mean duration of hospital stay was 46.4 hours (range $11 \mathrm{~h}-168 \mathrm{~h}$ ). In study of Hossein et at. ${ }^{5}$ mean duration of hospital stay was $49.5 \pm 38$. $1 \mathrm{~h}$ (range $12 \mathrm{~h}-216 \mathrm{~h}$ ) which is similar to this study. In our study, mean time to reach the hospital was 5.2 hours (range $3 h-12 h$ ). In other study all patients were referred to hospital within the first $10.5 \mathrm{~h}$ of exposure and the mean time was $4.7 \pm 2.9 \mathrm{~h}$ (range: $1-10.5 \mathrm{~h}$ ). ${ }^{5}$ In our study all cases were from Dhaka district except one that came from outside of capital. It also showed that the tendency for seeking of heath care facility among people in poisoning cases was better.

Mother's anxiety (6/11), keeping drugs in same containers (11/11), similarities of suppository's size, shape and color (11/11) were the main causes of mistakes by mothers of all profession in this study, but in other studies tramadol was mostly used for the therapeutic purpose like analgesic or unintentional oral exposure. ${ }^{5}$ Alizade et. al. showed in their study that family drug addiction was one of the causes of acute paediatric poisoing including tramadol poisoning which is different from our observation. ${ }^{14}$ In this study the main clinical features were drowsiness in $4(36 \%)$ cases, semi consciousness in $2(18 \%)$ cases but in study of Hossain et al, it was found that $70 \%$ cases had decreased level of consciousness, $15 \%$ experienced apnea, and $20 \%$ had nausea and vomiting.

Single case out of 11 got Injection naloxone as antidote in this study but in the study of Hossain et al. naloxone use was commonly used as in $85 \%$ cases. In most cases, two-thirds of the initial naloxone bolus dose which had reversed opioid effects was used per hours for six hours. It was then titrated every $6 \mathrm{~h}$ to achieve a normal consciousness level and preserve adequate respiration.In other studies in children it was showed that individual naloxone doses up to $0.4 \mathrm{mg} / \mathrm{kg}$ and constant intravenous infusion of $0.16 \mathrm{mg} / \mathrm{kg} / \mathrm{h}$ had not been associated with adverse effects. ${ }^{5,15}$ In this study ventilator was required in one case having septicemia. and one patient died. But in other study, it was found that none of the children required intubation and all patients were discharged without any complications with a significantly higher length of stay in apneic patients. ${ }^{5}$

\section{Conclusion}

Altered consciousness, respiratory difficulty are common features of tramadol suppository poisoning. Anxiety of parents and similarity in shape, size and color of paracetamol and glycerin suppository with that of tramadol, keeping in same container are main causes of mistakes. More cautiousness of parents, dissimilarity among different suppository in color shape, size and using of different containers of drugs may be the preventive way of this poisoning.

\section{References}

1. Beakley BD, Kaye AM and Kaye AD. Tramadol, pharmacology, side effects, and serotonin syndrome: a review.Pain Physician 2015; 18:395-400.

2. Grond S, Sablotzki A. Clinical pharmacology of tramadol. Clinical Pharmacokinetics 2004; 43:879-23.

3. Tramadol Update Review Report Agenda item 6.1 Expert Committee on Drug Dependence Thirty sixth Meeting Geneva, 16-20 June 2014

4. Sarkar S, Nebhinani N, Singh SM, Mattoo SK, and Basu D.Tramadol Dependence: A Case Series from India. J Psychol Med. 2012; 34: 283-85. 
5. Hossein M, Fariba F, Mitra R.Tramadol overdose and apnea in hospitalized children, a review of 20 cases. Res Pharm Sci. 2015; 10(6): 544-52.

6. Pendeville PE, Von MS, Dort JP, Veyckemans F. Double-blind randomized study of tramadol vs. paracetamol in analgesia after day-case tonsillectomy in children. Eur $J$ Anaesthesiol. 2000; 17:576-82.

7. Finkel JC, Rose JB, Schmitz ML, Birmingham PK, Ulma GA, Gunter JB, et al. An evaluation of the efficacy and tolerability of oral tramadol hydrochloride tablets for the treatment of postsurgical pain in children. AnesthAnalg. 2002; 94:1469-73.

8. Payne KA, Roelofse JA. Tramadol drops in children: analgesic efficacy, lack of respiratory effects, and normal recovery times. AnesthProg. 1999; 46:91-96.

9. Spiller HA, Gorman SE, Villalobos D, Benson BE, Ruskosky DR, Stancavage MM, et al. Prospective multicenter evaluation of tramadol exposure. J Toxicol Clin Toxicol. 1997; 35: 361-64.

10. Gholami K, Shalviri G, Zarbakhsh A, Daryabari $\mathrm{N}$, Yousefian S. New guideline for tramadol usage following adverse drug reactions reported to the Iranian Pharmacovigilance Center. Pharmacoepidemiol Drug Saf. 2007; 16: 229-37.

11. Grosek S, Mozina M, Grabnar I, Primozic J. Diagnostic and therapeutic value of naloxone after intoxication with tramadol in a young girl. Pediatr Int. 2009; 51:842-43.

12. Mazor SS, Feldman KW, Sugar NF, Sotero M. Pediatric tramadol ingestion resulting in seizure like activity: a case series. PediatrEmerg Care. 2008; 24:380-81.

13. Tanné C, Javouhey J, Millet A, Bordet F. Severe Tramadol Overdoses in Children: A Case Series Admitted to Paediatric Intensive Care Unit. J ClinToxicol 2016; 6:1-5

14. Alizadeh A, Asoudeh MZ, Abdi F, Moshiri M, Mood MB. et al. Epidemiological Pattern of Acute Pediatric Poisoning in Mashhad, Iran During 2011 - 2013, High Risk Behavlnt J Addict. 2017;6(2):e33707.

15. American Academy of Pediatrics Committee on Drugs: Naloxone dosage and route of administration for infants and children: addendum to emergency drug doses for infants and children. 1990; 86:484-85. 